\title{
SILICON-MEDIATED IMPROVEMENT IN TOLERANCE OF ECONOMICALLY IMPORTANT CROPS UNDER DROUGHT STRESS
}

\author{
PANG, Z. ${ }^{1,2}$ - TAYYAB, M. ${ }^{1,2}$ - ISLAM, W. ${ }^{3,4,5}$-TARIN, M. W. K. ${ }^{6}$ - SARFARAZ, R. ${ }^{7}$ - NAVEED, H. ${ }^{8}$ \\ - ZAMAN, S. ${ }^{9}-$ ZHANG, B. ${ }^{10}-$ YUAN, Z. ${ }^{1,2^{*}}-$ ZHANG, H..$^{1,2^{*}}$
}

${ }^{1}$ Key Laboratory of Sugarcane Biology and Genetic Breeding, Ministry of Agriculture, Fujian Agriculture and Forestry University, Fuzhou 350002, China

${ }^{2}$ College of Crop Science, Fujian Agriculture and Forestry University, Fuzhou 350002, China

${ }^{3}$ Key Laboratory for Humid Subtropical Eco-Geographical Processes of the Ministry of Education, Fujian Normal University, Fuzhou 350007, China

${ }^{4}$ Institute of Geography, Fujian Normal University, Fuzhou 350007, China

${ }^{5}$ Agriculture Department, Govt. of Punjab, Lahore, Pakistan

${ }^{6}$ College of Forestry, Fujian Agriculture and Forestry University Fuzhou 350002, China

${ }^{7}$ College of Resources and Environment, Fujian Agriculture and Forestry University, Fuzhou 350002, China

${ }^{8}$ Institute of Entomology, College of Life Sciences, Nankai University, Tianjin 300071, China

${ }^{9}$ Insitute of Entomology, University of Agriculture, Faisalabad 38000, Pakistan

${ }^{10}$ College of Biological Science and Biotechnology, Shenyang Agricultural University, Shenyang, China

*Corresponding authors

e-mail: yzn05@sina.com (Z.Yuan); zhanghua4553@sina.com (H. Zhang)

(Received 30 $0^{\text {th }}$ Aug 2018 ; accepted $8^{\text {th }}$ Apr 2019)

\begin{abstract}
Drought is considered as one of the significant threats to food security worldwide as it inhibits the growth, yield and quality of economically important crops. An increase in crop yield is considered a tremendous achievement as it will be helpful to meet the current growing demand for food in droughtstressed areas. Silicon ( $\mathrm{Si}$ ) is the second most abundant component in the soil. Recent research has revealed that $\mathrm{Si}$ can enhance plant tolerance against drought stress. In addition, application of Si can increase seed germination, underground and aboveground biomass, photosynthetic pigments, quality and yield of grains. Therefore, we have summarized the importance of Si in improving the drought tolerance in plants. Furthermore, we have explained the Si-mediated mechanisms which led to modifications in gas exchange properties, homeostasis of the nutrient element, synthesis of compatible solute, osmotic adjustments, antioxidant stimulation and enzymatic action in plants under drought stress. We believe that the current study will help in understanding the importance of Si application in plants under drought stress conditions.
\end{abstract}

Keywords: seed germination, antioxidants enzymes, drought tolerance, gene expression, soil 


\section{Introduction}

The increasing demand for food day by day is one of the significant challenges for agricultural scientists worldwide (Warner and Jones, 2017). On the other hand, the world's crop productivity is continually decreasing due to extreme climate changes and shrinking resources. In view of that, finding the new options to improve the crop productivity is a challenging task for all nations across the world (George et al., 2018; Lesk et al., 2016; Rizwan et al., 2018). Abiotic stresses (salt, drought, and extreme temperature stress) are the challenging problems for plant development and its productivity in many parts of the world (Khalil et al., 2016, 2018; Suzuki et al., 2014). Among these abiotic stresses, drought is one of the most harmful environmental factors which inhibit growth, yield and quality of economically important crops (Ali et al., 2016; Calvo-Polanco et al., 2016). Therefore, it is estimated to be one of the severe threats for future agricultural crop production (Khalil et al., 2018; Tayyab et al., 2018a). The negative impacts of drought stress on many plants have become the central debate in recent years (Tayyab et al., 2018a). Drought along with other abiotic stresses including heavy metal contamination not only restricts plant production but also poses severe threats to human health (Arshad et al., 2016; Noman and Aqeel, 2017). For example, Liu et al. (2017) revealed that under different growth stages, the translocation and redistribution of cadmium have a different influence for drought in peanut plants. It can affect the processes such as cell dehydration, the inhibition of cell expansion and division, stem elongation, leaf size, root proliferation, disturbed stomatal oscillations, water and nutrient absorption in plants (Kaushal and Wani, 2016; Khalil et al., 2018; Tayyab et al., 2018a). Furthermore, it also reduces photosynthesis (Khan et al., 2017; Zang et al., 2014), soil water potential, water use efficiency (WUE) (Kaushal and Wani, 2016), and induce oxygen deficiency by the production of reactive oxygen species (ROS) (Fukao et al., 2011). Consequently, combating the stress caused by drought is a serious matter to achieve food security in changing climate conditions around the world.

$\mathrm{Si}$ is found to be the second most abundant element in soil (Sommer et al., 2006). However, it comprises up to $10 \%$ dry weight of many plants. In the past, researchers could not find $\mathrm{Si}$ as an essential element for normal development and growth of the plant (Epstein, 1994; Hodson et al., 2005). However, concerning the Si efficiency on the plant's life cycle, Epstein and Bloom (2005) recommended that the proper need of Si element is significant for normal plant growth. Recently, numerous researches have demonstrated that Si mitigates the destructive effects of biotic stresses (pests and diseases) (Dann and Le, 2017; Yang et al., 2017) and abiotic stresses (drought, heavy metal toxicity and salinity) in plants (Biju et al., 2017; Hasanuzzaman et al., 2018; Tayyab et al., 2018b). These benefits are attributed to Si application; thus, Si can play a serious role in order to mitigate drought stress in plants. Moreover, sustainable agriculture has got great importance so it can be used as a high-quality fertilizer because of its non-corrosive and non-polluted nature. Si effect for plant growth and development in unfavorable climatic conditions has been reviewed by many researchers recently around the globe (Guntzer et al., 2012; Tayyab et al., 2018b; Van Bockhaven et al., 2012). Van Bockhaven et al. (2012) reviewed the role of Si for plant disease resistance. However, the mechanisms of Si-mediated mitigation of drought stress in plants are still debatable and need to be reviewed. Si application as a fertilizer for plants also has gained momentum recently. In order to enhance drought tolerance, Si application in term of soil amendment is expected to become a new approach in agricultural farming in the future. Therefore, we have reviewed the current status and progress in understanding the mechanisms of Si-mediated 
drought tolerance in plants. The review unveils the various mechanisms involved in the plant's protection during drought stress as well as suggests guidelines for further research.

\section{History of silicon application}

$\mathrm{Si}$ is widely distributed as silica or alumino-silicates - better known as rocks and sand. $\mathrm{Si}$ is not readily available for plants to use; instead plants can only absorb $\mathrm{Si}$ as a monosilicic acid (Marafon and Endres, 2013). Si is beneficial for plants, such as protecting against diseases, insects attacks, reinforcing nutrients and safeguarding under unfavorable conditions like drought, salt or heavy metals toxicity (Debona et al., 2017; Tayyab et al., 2018b). Kutschera and Niklas (2018) highlighted the function of Si in plant biology as "whether silicic acid is an indispensable substance for those plants that contain silica, whether it takes part in the nutritional processes, and what is the relationship that exists between the uptake of silicic acid and the life of the plant?" (Lewin and Reimann, 1969). In the $20^{\text {th }}$ century, several trials were directed on Si to demonstrate its beneficial role in agriculture owing to its safe behavior and presence in nature. For the first time in the world, rice (Oryza sativa) soils in Japan were treated with Si in 1955 (Takahashi et al., 1990). Si fertilizers commonly contain neutral or slightly alkaline $\mathrm{pH}$ which has the neutralizing effect for acidic soils (Savant et al., 1999). Several kinds of Si fertilizers are applied in the field usually in the form of solids as well as liquids such as calcium silicates, calcium and magnesium silicates wollastonite, potassium silicate and sodium silicate.

\section{Silicon in soils}

Si contributes to the second major element existing in soil (Sommer et al., 2006). Si reacts with oxygen and turns into silicates, i.e., feldspars and quartz (Fig. 1). Silicate formed by oxygen and pure $\mathrm{Si}$ is known as silica (i.e., quartz) whereas other silicates (i.e., feldspars) have some elements (sodium, potassium, aluminum, and calcium) including oxygen and $\mathrm{Si}$. Soils are formed as the results of weathering of rocks made from aluminosilicates and silicates minerals. By biological and physical weathering silicate minerals release $\mathrm{Si}$ into soil solution that formulates silicic acid $\left(\mathrm{H}_{4} \mathrm{SiO}_{4}\right)$. Then, plant roots absorb silicic acid from soil solution (Epstein, 2009). The plant contains a significant amount of $\mathrm{Si}$ owing to its ubiquitous nature and abundance (Epstein, 1999). Si abundance and concentration fluctuates with the soil type. Typically, upper horizons frequently have low Si concentrations in the sandy soils (Marschner, 2011), whereas clay soils have higher phyllo-silicates quantities that release $\mathrm{Si}$. The quartz $\left(\mathrm{SiO}_{2}\right)$ mineral is abundantly present in sandy soils which are less prone to decomposition. The complexity of quartz mineral makes sandy soil more responsive to $\mathrm{Si}$ application than clayey soil (Demattê et al., 2011). In tropical and subtropical soils, Si commonly is found very low due to desilication because of leaching and some weathering processes (Epstein, 1999). Additionally, it is predicted that 210 to 224 million tons of $\mathrm{Si}$ have been removed by intensive arable cultivation throughout the world (Meena et al., 2014).

\section{Silicon uptake and accumulation in plants}

Plants differ in their ability to uptaking the Si. Some plants can accumulate more $\mathrm{Si}$ in their leaves and those with more than $1.5 \%$ of their total dry biomass are known as 
accumulators. Plants containing Si levels less than $0.5 \%$ in their leaves are considered as non-accumulators (Marafon and Endres, 2013). Variation of Si concentration in plants is attributed to their Si uptake capability and roots xylem loading (Ma et al., 2001a). The plasma membrane present in plant root cells might provide a path for uncharged monomeric $\mathrm{H}_{4} \mathrm{SiO}_{4}$ uptake by diffusion. Thus, $\mathrm{H}_{4} \mathrm{SiO}_{4}$ permeability coefficient of $10^{-10} \mathrm{~ms}^{-1}$ throughout a plasma membrane (Raven, 2001), does not clarify experimentally measured Si contents in plants (Tamai and Ma, 2003). Passive and active transporters are involved in the Si uptake and transport from growth medium to xylem tissues (Mitani et al., 2005). This hypothesis was confirmed due to Si uptake inhibition as plants were exposed to metabolic inhibitors (i.e., 2,4- dinitrophenol, potassium cyanide) or low temperature (Mitani et al., 2005; Tamai and Ma, 2003). A low-affinity silicic acid transporter involves Si transportation from root medium to cortical cells. Kinetic studies for Si uptake in rice (O. sativa), tomato (Solanum lycopersicum) and cucumber (Cucumis sativus) confirmed that the density of transporters present in the plasma membrane is responsible for Si uptake changes (Mitani et al., 2005). Recently, Lsil, Lsi2, and Lsi6 genes are associated with Si uptake and distribution in rice (O. sativa), barley (Hordeum vulgare), maize (Z. mays), and cucumber (C. sativus) (Ma and Yamaji, 2015). Si-influx transporters (Lsil and LsiG) are associated with Si distribution in the tissues of root and shoot (Mitani et al., 2011). Whereas, putative anion transporter (Lsi2) is commonly expressed in roots endodermis (Ma et al., 2007). Ma et al. (2007) reported that Lsi2 transporter activity is proton-driven and acts as a $\mathrm{Si} / \mathrm{H}^{+}$antiport.

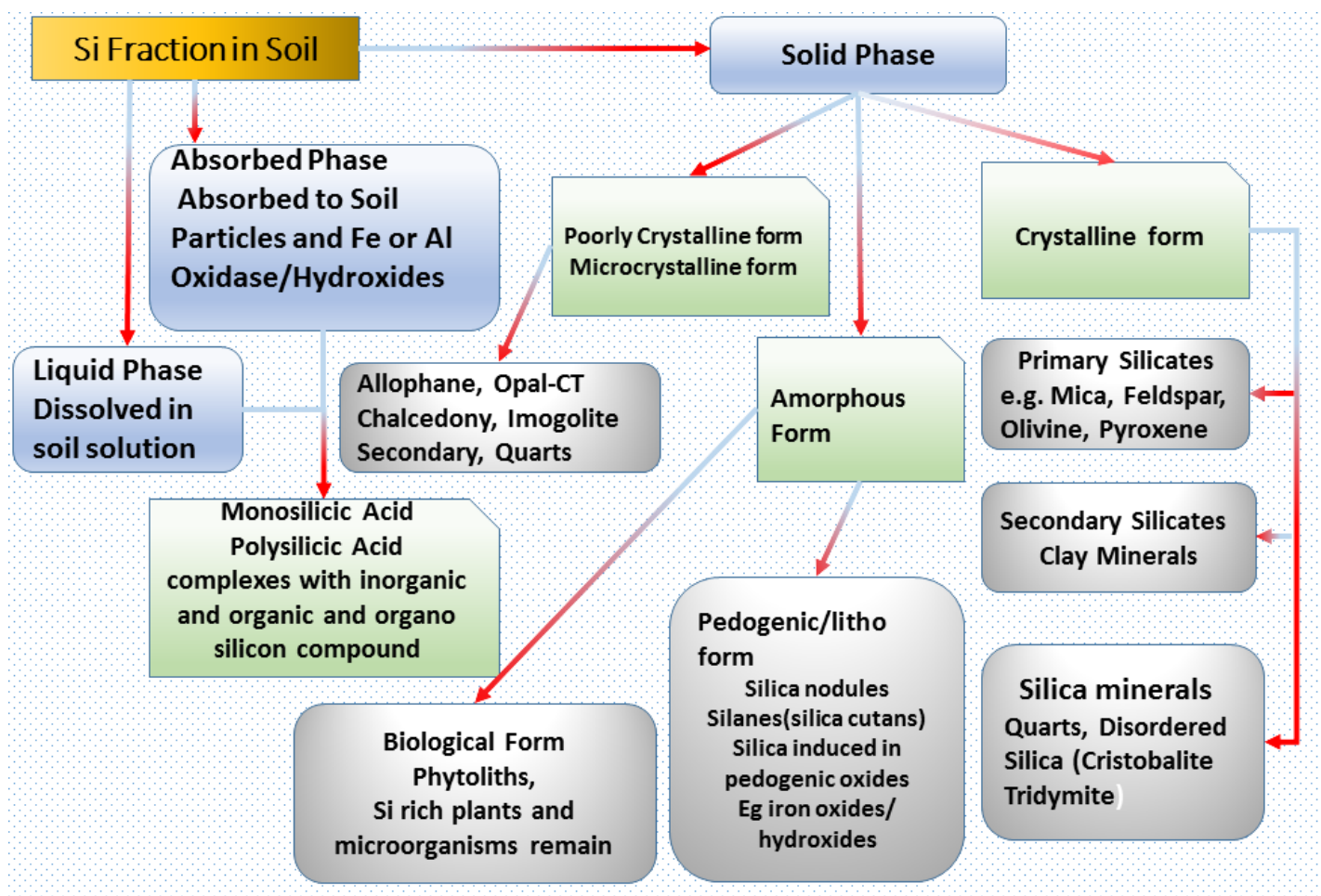

Figure 1. Various sources of silicon in the soil. (Modified from Zia, 2018)

\section{Silicon and drought stress}

Drought commonly reduces plant growth and its yield in semiarid and arid regions throughout the world (Zandalinas et al., 2018). It adversely affects plant biomass and 
growth of all crops cultivated in main fields as well (Kaushal and Wani, 2016). In contrast, various researchers have demonstrated that Si should consider being a practical approach to overcome these opposing effects stimulated by drought (Guo et al., 2017; Shi et al., 2014). The mechanisms in order to enhance drought tolerance in the plant by $\mathrm{Si}$ application at the morphological, physiological and biochemical levels are summarized below (see also Fig. 2).

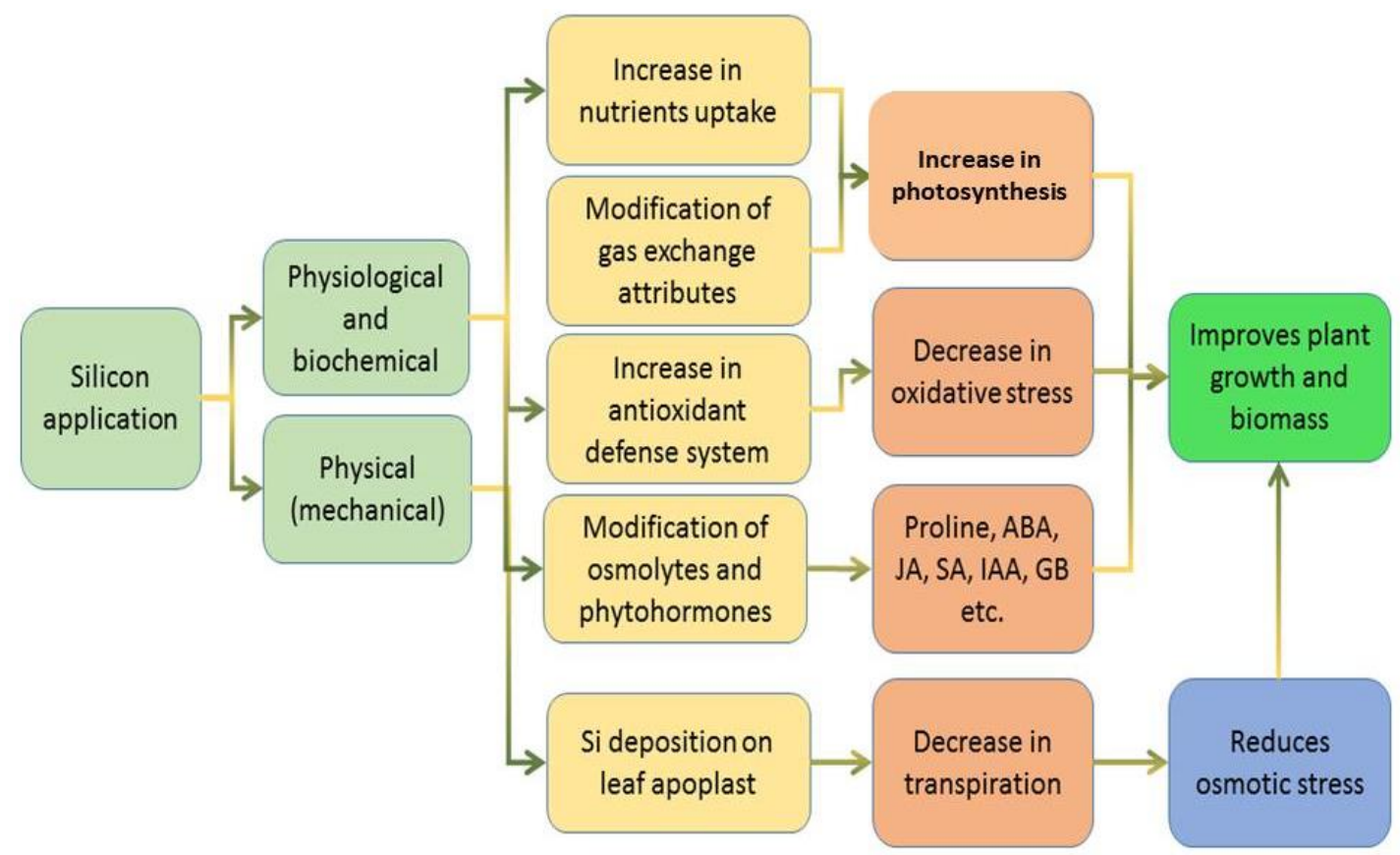

Figure 2. The mechanism for the Si-mediated alleviation of drought stress tolerance in plants. (Modified from Rizwan et al., 2015; Tayyab et al., 2018b)

\section{Si-mediated improvement in seed germination under drought condition}

Drought stress negatively affects the seed germination leading to considerable reduction in crop yield (Guo et al., 2017; Shi et al., 2014). Until now, a little research was conducted to study the $\mathrm{Si}$ effects for seed germination under drought conditions (Ahmed et al., 2016; Hasanuzzaman et al., 2018). On the contrary, Si not only mitigates the adverse effect induced by drought stress on seed germination but also promotes seed development. For instance, seed priming with sodium silicate contributed to recovering wheat (Triticum aestivum) seed germination compared to untreated seeds (Hameed et al., 2013). The authors described that soaking of seeds for $8 \mathrm{~h}$ in aerated solutions of $20 \mathrm{mM}, 40 \mathrm{mM}$ and $60 \mathrm{mM}$ sodium silicate resulted in $97 \%$ improvement in seed germination under water-deficit stress induced by $15 \%$ polyethylene glycol (PEG)6000 (Hameed et al., 2013). Similarly, Ahmed et al. (2016) reported seeds priming with $\mathrm{Si}$ (silicic acid, sodium silicate, and silica gel) at different concentration $(0.5 \%, 1.0 \%$, and $1.5 \%$ ) to explore its potential benefits fir couple of wheat (T. aestivum) varieties. The authors have shown that silica gel can be used as an active priming practice at $1.5 \%$ concentration for better development of a plant under drought conditions. Likewise, calcium silicate employed in the soil in the same conditions enhanced seed germination of maize (Z. mays; 15 different cultivars) up to $80.96 \%$ under water stress (under rainfed conditions) (Zargar and Agnihotri, 2013). Shi et al. (2014) reported that the Si 
application improved the seed germination in four tomatoes (S. lycopersicum) cultivars under drought as compared to control (without $\mathrm{Si}$ ). The authors investigated the effects of exogenous $\mathrm{Si}(0.5 \mathrm{mM})$ to tomato (S. lycopersicum) bud seedlings under water deficit stress simulated by $10 \%$ (w/v) PEG-6000 in four different cultivars ('Jinpengchaoguan', 'Zhongza No.9', 'Houpi L402' and 'Oubao318'), which significantly improved the seed germination by $21.9 \%$ - 38.2\% (Shi et al., 2014). Similarly, in a recent study, Hasanuzzaman et al. (2018) revealed that application of $\mathrm{Si}$ is also an active practice for the alleviation of the destructive effects of drought on seed germination in Brassica napus. Furthermore, Si application improved the vigor of seedlings. These reports demonstrate that $\mathrm{Si}$ can be effective to mitigate the destructive effects of drought on seed germination of crop plants. However, the general mechanisms must be explored for well understanding of Si functions in seedlings under drought conditions.

\section{Silicon-mediated improvement in plant growth, biomass, and photosynthesis under drought stress}

Plant biomass and growth is severely reduced by drought (Amin et al., 2016; Noman et al., 2015), hence the application of Si under drought stress can be considered a practical approach to improve plant biomass and growth. Si should be used in conditions effective for its activity and approach to improve plant growth and biomass under drought stress (Hajiboland et al., 2017; Merwad et al., 2018). Si employed in wheat ( $T$. aestivum) grown soil resulted in increased root biomass, shoots, spike weight and dry weight (Ahmad et al., 2007; Gong et al., 2003; Xu et al., 2017). Ratnakumar et al. (2016) reported that foliar application of $\mathrm{Si}(0,8,16,32 \mathrm{ppm}$ at different plant growth stages such as vegetative, booting and seed development stage) on wheat ( $T$. aestivum) in the form of ortho-silicic acid improved the root length, density and growth. In another study shoot and root lengths were improved via seed priming by sodium silicate under PEG-6000-induced drought (Hameed et al., 2013). Similarly, Si supply improved roots and shoot fresh weight of Kentucky bluegrass (Poa pratensis) under water stress. The daily amount of water or Si solution was $250 \mathrm{~mL}$ per pot. For $14 \mathrm{~d}$, plants were treated with $0,0.1$, and $1.0 \mathrm{mM} \mathrm{Si}$ solution for $\mathrm{Si}$ treatments and with distilled water for the control (Bae et al., 2017). Application of Si (seed primiprovided the better results of grain yield of wheat ( $T$. aestivum) grown under drought in hydroponics in pots and field experiments (Ahmed et al., 2016; Gharineh and Karmollachaab, 2013; Pei et al., 2010). Seed priming combined with other sources of Si improved the grain yield and spike length of the wheat (T. aestivum) crop as compared to control without seed priming under drought (Ahmed et al., 2016). The authors used seeds of two wheat varieties, i.e., NARC-2009 and Chakwal-50 which were sown in pots after priming with distilled water and different concentration $(0.5 \%, 1.0 \%, 1.5 \%)$ of Si sources (silicic acid, sodium silicate and silica gel). Maximum Si uptake at three leaves $(0.028 \mu \mathrm{g} \mathrm{g}-1$ dry weight (DW), anthesis $(0.072 \mu \mathrm{g} g-1 \mathrm{DW})$ and maturity $(0.103 \mu \mathrm{g} \mathrm{g}-1 \mathrm{DW})$ were recorded for silica gel (15\%) (Ahmed et al., 2016). Similarly, the use of Si (potassium silicate) employed on sorghum (Sorghum bicolor) resulted in improved roots dry weight by 30\% under drought (Ahmed et al., 2011). In a recent study, Si used as fertilizer in sugarcane field enhanced sugarcane (Saccharum officinarum) stalk yield, dry biomass and provided the best product under drought (de Camargo et al., 2017). Si applied in soil or through foliar application in the field (five sprays of $1.425 \mathrm{mM} \mathrm{Si}$ water solution), resulted in improved potato (Solanum tuberosum) yield and dry tuber weight just similar to well-irrigated potato ( $S$. 
tuberosum) plants (Pilon et al., 2014). Similarly, the application of Si improved the total root length, root surface area, volume and dry weight of rice (O. sativa) plants under drought (Ming et al., 2012). However, Nolla et al. (2012) and Moro et al. (2015) demonstrated rice (O. sativa) grain yield and plant height improvement by adopting the silicate in soil under drought conditions. Soybean (Glycine max) plant shoot length and dry and fresh weight were improved by use of Si under drought (Hamayun et al., 2010). The authors further explained that the adverse effects of PEG-induced drought were alleviated by adding and $200 \mathrm{mg} \mathrm{L}^{-1} \mathrm{Si}$ to the drought-stressed treatments (Hamayun et al., 2010). Diatomite application in soil provided effective results by improving growth parameter (shoots and roots length) and yield parameters (number of pods, fresh and dry weight of pod) in white lupine (Lupinus albus L.) under drought (Abdalla, 2011). Si increased leaf area index in numerous plant species, e.g., wheat (T. aestivum) and Fennel (Foeniculum vulgar Mill) under drought (Asgharipour and Mosapour, 2016; Gong et al., 2003). The application Si (300 kg of ha-1) increased the quantity of spikelet panicle and grain yield of rice; furthermore, dry matter recovery and yield had a positive linear relationship with shoot Si under drought (Ullah et al., 2017). The application of Si on two maize (Z. mays) varieties (hybrid P-33H25 and FH-810) increased the height of plant, stem diameter, number of leaves, cob length, the number of grain/cob, grain yield, and biological yield, which ultimately contributed to better growth and yield (Amin et al., 2016). The application of Si for tobacco (Nicotiana Rustica L.) has increased the biomass particularly aboveground parts in drought and control conditions (Hajiboland et al., 2017). Correspondingly, Si application on cowpea increased the yield per plant (Merwad et al., 2018).

Additionally, Si has also progressive influences on straw and grain quality of plants in drought conditions, but unfortunately, the studies are minimal. For example, Si (0.03 mM sodium selenite/ $1.5 \mathrm{mM}$ potassium silicate) application has a direct relation to levels of phenolic compounds, amylose and flavonoid contents of rice grains. It also increased the lignin, cellulose, pectin, carbohydrates, proteins and fat contents of rice straw under drought conditions in a field experiment (Emam et al., 2014). So, it is necessary to clarify further mechanisms to improve the quality of cereals mediated by $\mathrm{Si}$ application under drought, especially at the molecular level. Drought stress is the primary driver which significantly reduces the photosynthesis in plants. On the other hand, various studies have exposed that by absorbing $\mathrm{Si}$, photosynthetic pigments can be increased in various plant species (Hasanuzzaman et al., 2018; Merwad et al., 2018). The application of Si on wheat (T. aestivum) plants showed better result by improving the leaves chlorophyll content (Ma et al., 2016), and photosynthesis rate (Sattar et al., 2017). Likewise, Maghsoudi et al. (2016) demonstrated that Si leaf application increased photosynthesis pigments (chlorophyll a, b and total land carotenoids) and chlorophyll stability index (CSI) in different wheat ( $T$. aestivum) cultivars under drought conditions. Similarly, Si foliar application on wheat increased leaf chlorophyll content (Ratnakumar et al., 2016). Si usage protected rapeseed (B. napus) leaves photosynthetic pigments (Hasanuzzaman et al., 2018), and increased total chlorophyll content of soybean (G. max) leaves under drought (Shen et al., 2010). Si was also observed to improve the allocation of light absorbed between PSII and PSI in the chloroplasts of tomato (S. lycopersicum) leaves and maintain the chloroplast membrane structure under drought (Cao et al., 2015). Moreover, $\mathrm{Si}\left(\mathrm{K}_{2} \mathrm{SiO}_{3}\right.$ at the rate of $2.25 \mathrm{mM}$ ) increased photosynthesis and chlorophyll content of two cucumber cultivars (C. sativus) under drought (Ouzounidou et al., 2016). 
In a recent study, Merwad et al. (2018) revealed that Si foliar application on cowpea (Vigna unguiculata) leaves improved chlorophyll (a, b, and total carotenoids) contents. Moreover, chlorophyll content and chlorophyll ratio (a:b) in chestnut leaves was improved under drought condition, when $\mathrm{Si}$ (Sili-K® solution containing $0.12 \% \mathrm{Si}$ and $0.15 \% \mathrm{~K})$ was repeatedly $(\times 3)$ sprayed onto leaves of potted chestnut plantlets and irrigation was suspended for 7 weeks (Zhang et al., 2013). Application of Si on two different rice cultivars (Curinga and IAC-202) enhanced the photosynthetic rate which was reduced by the lack of water (Moro et al., 2015). Soil or foliar applied Si enhanced chlorophyll (a and carotenoids) concentration and chlorophyll (a/b ratio) similar to wellirrigated potato (S. tuberosum) plants (Pilon et al., 2014). Si foliar application significantly increased the net photosynthesis rate, green leaf color of Blue Kentucky grass (P. pratensis) leaves (Saud et al., 2014), whereas enhanced photochemical efficiency and photosynthetic rate of Cacao (Theobroma cacao) leave under drought conditions (Zanetti et al., 2016).

\section{Impacts of Si application under drought stress}

Si use exhibited positive influences on seed germination, photosynthesis, plant growth and biomass under drought circumstances in the previous segment. These affirmative effects can be owing to various mechanisms such as enhancement of nutrient uptake by plants, by adjusting osmotic potential, by modifying the gaseous exchange attributes, decrease the oxidative stress and by an alteration in expressing of the gene in plants. Details of these mechanisms are given in (Fig. 2).

\section{Oxidative stress}

Dry conditions damage the photosynthetic pigments and disturb the balance between ROS production and antioxidants thus affect overall crop production (Kim et al., 2017). Through up-regulation of antioxidant activities of catalase (CAT), superoxide dismutase (SOD), and growth regulators (GR), Si treatment of wheat plants resulted in higher drought tolerance (Gong et al., 2005). Si supplements in wheat plants of wheat ( $T$. aestivum) shown lesser contents of glutathione, lipid peroxidation and total flavonoid while raised content of ascorbate with Si application (Ma and Takahashi, 2002). Similarly, in tomato plants, $\mathrm{Si}$ supplementation upon polyethylene glycol (PEG) induced drought stress resulted in tolerance through increased activities of CAT and SOD along with the enhanced roots ability of water uptake (Shi et al., 2014). Moreover, $\mathrm{Si}$ reduced the activities of ascorbate peroxide (APX), under drought conditions in sunflower (Helianthus annuus) (Gunes et al., 2008b).

Drought stress produces ROS in plants triggering oxidative stress damage (Fukao et al., 2011; Noman et al., 2015). Various research communities revealed that Si supply increases the antioxidant enzymes activities while decreased oxidative damage stress in plants which can be adequate to the progression of plant drought tolerance (Bae et al., 2017; Hajiboland et al., 2017; Ma et al., 2016). Si application reduced the lipid peroxidation and hydrogen peroxide $\left(\mathrm{H}_{2} \mathrm{O}_{2}\right)$ of sunflower $(\mathrm{H}$. annuus), chickpea (Cicer arietinum) (Gunes et al., 2007, 2008b), and lentil (Lens culinaris) plants leave under drought conditions (Biju et al., 2017). Similarly, $\mathrm{H}_{2} \mathrm{O}_{2}$ and lipid peroxidation were reduced in rapeseed (B. napus) leaves (Hasanuzzaman et al., 2018), decreased $\mathrm{H}_{2} \mathrm{O}_{2}$ contents in tobacco (Nicotiana tabacum) (Hajiboland et al., 2017), and wheat (T. aestivum) leaves (Gong et al., 2008; Ma et al., 2016). Xu et al. (2017) described that 
usage of $\mathrm{Si}$ (potassium silicate $1.0 \mathrm{mM}$ ) significantly decreased $\mathrm{H}_{2} \mathrm{O}_{2}$, malondialdehyde (MDA) contents, and increased superoxide dismutase (SOD) activities in leaves of wheat during drought by Si supplementation (Gharineh and Karmollachaab, 2013). In addition, Pei et al. (2010) stated that the $\mathrm{Si}(1 \mathrm{mM})$-supplying reduced $\mathrm{H}_{2} \mathrm{O}_{2}$, MDA in wheat ( $T$. aestivum) leaves and Chinese liquorice (Glycyrrhiza uralensis), under drought conditions induced by $100 \mathrm{mM} \mathrm{NaCl}$ with 0,10 and 20\% of PEG-6000 (Zhang et al., 2017). Si supplementation in soil decreased the Lipid peroxidation (LP) in white lupin (L. albus) (Abdalla, 2011). Shi et al. (2014) demonstrated that Si addition improved superoxide dismutase (SOD), catalase activities (CAT), and $\mathrm{H}_{2} \mathrm{O}_{2}$ in bud radicles than non-Si treated tomato ( $S$. lycopersicum) seedlings. Similarly, Si supply enhanced antioxidant activity, including SOD, CAT and decreased $\mathrm{H}_{2} \mathrm{O}_{2}$ \& MDA contents in tomato (S. lycopersicum) (Cao et al., 2017). Additionally, Si application considerably enhanced peroxidase (POD) and SOD in the Canola (B. napus) plants activities (Habibi, 2014). Furthermore, the application of Si improved ascorbate peroxidase activity (APX) and glutathione (GSH) contents in Chinese liquorice (Glycyrrhiza uralensis) under drought than non-Si treatments (Zhang et al., 2017). The antioxidant enzyme's activity (e.g., SOD and CAT) was increased by Si application in wheat (T. aestivum) (Sattar et al., 2017), Cowpea (V. unguiculata) (Merwad et al., 2018) and in potato's plants ( $S$. tuberosum) by foliar application of Si under drought (Pilon et al., 2014).

Moro et al. (2015) revealed that the use of Si was effective to increase rice SOD, CAT and APX activities and similarly, CAT, POD, SOD and $\mathrm{H}_{2} \mathrm{O}_{2}$ were enhanced in soybean (G. max) (Shen et al., 2010) and Kentucky bluegrass ( $P$. pratensis) during drought stress (Bae et al., 2017). Hasanuzzaman et al. (2018) noted that CAT, APX enhanced in rapeseed (B. napus) and similarly SOD activity of mango (Mangifera indica) leaves (Helaly et al., 2017). Moreover, SOD, CAT, APX, and POD were enhanced in the wheat (T. aestivum) (Tale and Haddad, 2011), chickpea (C. arietinum) shoot (Gunes et al., 2007) and tomato (S. lycopersicum) as compared to non-Si supplemented plants (Shi et al., 2014). Actions of SOD and POD decreased by the Si use and increased CAT activity of cucumber ( $C$. sativus) plants than to Si-deficient plants (Ma et al., 2004). Impact of Si on the antioxidant enzyme of plants not only fluctuates with the changes of plant species but also depends on the plant stages of growth during drought (Gong et al., 2008). However, reports are limited on Si's functions on the antioxidant enzyme actions at various growth periods of the plant. For instance, the activities of APX, SOD and the CAT were not improved at the booting stage however improved the SOD while decreased APX activity at the filling stage of wheat (T. aestivum) during drought (Gong et al., 2008). Improvement of non-enzymatic antioxidants contents can provide best results to decrease the plant oxidative stress. Various reports revealed that levels of the nonenzymatic antioxidants of different species of plant could be affected by the Si application (Gong et al., 2005; Pei et al., 2010). For example, the Glutathione reductase (GSH) activity (Gong et al., 2005) and ascorbic acid (AA) concentration were improved through the use of the Si during drought conditions in wheat (T. aestivum) (Pei et al., 2010). In deduction, Si application reduced the oxidative stress and increased antioxidant enzymes activities.

\section{Plant nutrients uptake}

The plants need sufficient quantity of the essential nutrients for proper development and growth, but nutrients uptake in plants is disturbed under drought conditions (Emam et al., 2014; Merwad et al., 2018; Ratnakumar et al., 2016). However, Si has positive 
effects on nutrients uptake in plants under drought. For instance, by the application of $\mathrm{Si}$, Potassium (K) and the total Phosphorus (P) level were enhanced straw of wheat $(T$. aestivum) seed (Ratnakumar et al., 2016), and rice (O. sativa) straw (Emam et al., 2014) and leaf $\mathrm{P}$ in wheat (T. aestivum) (Gong and Chen, 2012). Additionally, it was also effective to improve $\mathrm{N}, \mathrm{P}$ and $\mathrm{K}$ of seed and shoot of cowpea ( $V$. unguiculata) plants (Merwad et al., 2018). In addition, Calcium (Ca) and $\mathrm{K}$ content increase in wheat ( $T$. aestivum) leaf and roots was observed (Kaya et al., 2006). Correspondingly, Kentucky Bluegrass ( $P$. pratensis) (root, shoot and leaf) C: $\mathrm{N}$ ratio improved by the supply of $\mathrm{Si}$ under drought (Saud et al., 2014). Gunes et al. (2008a) noted that Si supply in soil enhanced the macronutrients $(\mathrm{Ca}, \mathrm{K}, \mathrm{P}, \mathrm{Mg})$ and the micronutrients $(\mathrm{Cu} \mathrm{Fe}$, and $\mathrm{Mn}$ ) uptake of sunflower $(H$. annuus) cultivar under drought. Exogenous Si supply was effective for wheat ( $T$. aestivum) plant growth by modifying the nutrient uptake ( $\mathrm{Si}, \mathrm{Na}$ and $\mathrm{Mg}$ ) (Xu et al., 2017), and improve (N, P, and K) uptake in different species of grass (Eneji et al., 2008). Contrarily, reports show that the nutrients uptake reduced in a plant with the supply of $\mathrm{Si}$ (Chen et al., 2011). For instance, in rice (O. sativa) plants $\mathrm{Ca}, \mathrm{K}, \mathrm{Mg}$, and $\mathrm{Fe}$ contents were increased by drought, on the other hand, Si supply reduces these nutrients in plants (Chen et al., 2011).

\section{Regulating osmotic potential}

Optimal water level plays a significant role in plants existence under drought. Generally, plants maintain a high water level through osmotic adjustment under dry stress circumstances (Blum, 2017). Although, high drought circumstances trigger a considerable reduction in water content of leaf including water potential in various plants (Abid et al., 2018; Paz-Kagan et al., 2017; Sattar et al., 2017). Various literature highlighted that Si supply extensively enhanced the water potential of plant's leaf and water content under a dry spell (Hasanuzzaman et al., 2018; Ming et al., 2012; Ratnakumar et al., 2016). For instance, supply of Si enhanced water contents in wheat (T. aestivum) (Ratnakumar et al., 2016; Sattar et al., 2017; Tale and Haddad, 2011, rapeseed (B. napus) (Hasanuzzaman et al., 2018), rice (O. sativa) (Ming et al., 2012), chickpea (C. arietinum) (Fawaz and Mohammad, 2013), sunflower (H. annuus) (Gunes et al., 2008b), cucumber (C. sativus) (Ma et al., 2004), and sorghum ( $S$. bicolor) (Sonobe et al., 2010) under drought.

Application of Si enhanced the osmotic, relative water contents, turgor and water potential of wheat (T. aestivum) flag leaf (Sattar et al., 2017). Such as the water content of wheat (T. aestivum) was increased during drought (Ratnakumar et al., 2016). Si use improved the leaf relative water content in cowpea ( $V$. unguiculata) (Merwad et al., 2018), rapeseed (Brassica napus L.) (Hasanuzzaman et al., 2018), Kentucky bluegrass (P. pratensis) (Saud et al., 2014) and maize (Z. mays) plants (Amin et al., 2014). On the other hand, under drought Si reduced the osmotic potential of roots in sorghum $(S$. bicolor) without interrupting water contents (Sonobe et al., 2010). Osmotic adjustment is consequence owing to soluble amino acids (alanine and glutamic acid) and sugars. Yin et al. (2014) revealed that Si reduced the proline content and osmotic potential of sorghum (S. bicolor) leaf whereas enhanced soluble sugar. Authors proposed that the osmotic adjustment does not contribute to Si mediated rise in drought tolerance in the sorghum $(S$. bicolor). The water content of leaf and the water potential improved by the supply of $\mathrm{Si}$ are accredited to a thickness of wheat (T. aestivum) leaves (Gong et al., 2003). Furthermore, leaf water potential enhancement might be triggered by $\mathrm{Si}$ 
deposition in the leaves. Additionally, deposition of Si on leaf surface might reduce transpiration through controlling molecules of water (Keller et al., 2015).

\section{Regulation of osmolytes and phytohormones}

Osmolytes and phytohormones roles have been already well described for tolerance of plants at different stresses (Kurepin et al., 2017; Zhang et al., 2017). Various studies demonstrated about Si application improving plant tolerance against drought through modifications of osmolytes in different species of plants (Hamayun et al., 2010; Hasanuzzaman et al., 2018; Xu et al., 2017). Si was effective to enhance proline, a nonprotein amino acid, but total sugar and soluble protein were decreased in potato $(S$. tuberosum) leaves (Crusciol et al., 2009). On a similar note, use of Si improved proline contents in the wheat (T. aestivum) (Gong et al., 2005), pepper (Capsicum annuum) (Pereira et al., 2013) and rapeseed (B. napus) plant (Hasanuzzaman et al., 2018). Proline is frequently measured as an osmotic protector which may be effective to support plants against drought. However, studies associated with Si supply effects on plants growth hormones are limited under drought condition. Si supply declined Jasmonic acid (JA) level but enhanced salicylic acid (SA) levels in shoots of soybean plant (Hamayun et al., 2010) and pepper (C. annuum) plants, nitrate reductase activity (Pereira et al., 2013). The study demonstrated that the $\mathrm{Si}$ could be effective to enhance tolerance against drought in the plant through improvement in nitrogen metabolism and signaling of phytohormones. Yin et al. (2014) revealed that the use of Si increased sorghum $(S$. bicolor) drought resistance through regulation of 1-aminocyclopropane-1-carboxylic acid and polyamine synthesis.

\section{Regulation of gene expression}

In the first report, Si supply was effective to enhance aquaporin genes expression under drought which prompted water uptake in sorghum (S. bicolor) roots (Liu et al., 2014). Also, the Si supply enhanced up-regulation of conjugated polyamines synthesis genes in sorghum (S. bicolor) during drought condition (Yin et al., 2014). Khattab et al. (2014) demonstrated that $\mathrm{Si}$ supply improved expression of the ring domain carrying protein (OsRDCP1), drought-related protein (OsCMO) and coding choline monooxygenase and dehydrin (OsRAB16b) in rice (O. sativa) plants of rice. So far, a mechanism of Si-mediated gene expression under alleviation of drought stress is poorly understood; therefore more efforts are required to uncover this aspect.

\section{Regulating gaseous exchange}

Leaf gas exchange attributes to deliver beneficial evidence on plant mechanisms in stressed conditions (Chen et al., 2011; Liu et al., 2014). Especially under drought conditions, the stomata regulate the water level of the plant by adjusting the rate of transpiration. Countless studies raveled that supply of the Si regulates plant's gaseous exchange attributes as plant are exposed to the drought (Hajiboland et al., 2017; Ming et al., 2012; Pereira et al., 2013; Saud et al., 2014). For example, the supply of diatomite in the soil provided a reduction in white lupine plants transpiration rate by improving stomatal conductance and the rate of photosynthesis (Abdalla, 2011). Similarly, Hattori et al. (2005) noted a higher transpiration rate and stomatal conductance in plants of sorghum (S. bicolor) during drought than without Si supply control plants. The authors concluded that maintenance of higher water level in sorghum (S. bicolor) plants was 
because of higher water absorption in the existence of Si. Correspondingly, under drought $\mathrm{Si}$ use improved the transpiration and net photosynthesis rate in the rice $(O$. sativa) (Ming et al., 2012), pepper (C. annuum) plants (Pereira et al., 2013) and soybean (G. max) (Shen et al., 2010).

Furthermore, the use of $\mathrm{Si}$ enhanced rate of transpiration and the stomatal conductance in sorghum (S. bicolor) seedling (Liu et al., 2014). Gao et al. (2005) noted that Si supply improved WUE in the drought stress maize (Z. mays) through a reduction in transpiration rate of the leaf by stomata showed that the Si effects stomatal drive in the plant. Authors suggested that the rate of stomatal transpiration was decreased whereas stomatal density and morphology cannot clarify Si to decrease the rate of stomatal transpiration in maize (Z. mays) (Gao et al., 2006). Si use improved the rate of photosynthesis whereas the reduced rate of transpiration under drought condition in Tobacco (N. Rustica) (Hajiboland et al., 2017) and in plants of maize (Amin et al., 2014). Furthermore, the increase in WUE by Si supply was noted in chickpea $(C$. arietinum), (Fawaz and Mohammad, 2013), cacao (Theobroma cacao) grown in pots (Zanetti et al., 2016), wheat (T. aestivum) grown-up in the hydroponics (Ding et al., 2007) and wheat (T. aestivum) grown in field condition in drought (Gong and Chen, 2012). Gong et al. (2005) proposed that the use of Si on wheat (T. aestivum) was grown in the pots, shown an increased level in net $\mathrm{CO}_{2}$ incorporation rate of the leaves during drought. The study is limited associated with the diurnal changes of plant gas exchanges characteristics with a supply of Si in drought. Gong and Chen (2012) revealed that Si use was effective for diurnal change in the net photosynthetic rate of leaf, the rate of transpiration and the stomatal conductance of plants of wheat (T. aestivum) in the field condition under drought. Likewise, Ma et al. (2004) noted Si mediated diurnal change in the gas exchange characteristic in plants of cucumber (C. sativus) in drought.

\section{Conclusion and perspective}

Since 1999, many studies have been carried out to enlist benefits of Si for plant growth, but still, there is a lack of application of $\mathrm{Si}$ as a fertilizer for agronomic and horticulture benefits. Here is a dire need to create awareness about Si benefits among the masses and estimate its economic prospects. Therefore, the main aim of this review is to explain the mechanisms of the Si mediated mitigation of droughts in the plant. Available literature demonstrated that $\mathrm{Si}$ supplementation was sufficient to improve biomass, plant growth, seed germination, and photosynthesis drought stress condition. Si supply increased biomass and plant growth during a drought might be due to various mechanisms. This review can assist in well understanding mechanism of Si-arbitrated development in plants drought tolerance. Moreover, it could be effective to understand how crop production can be increased in drought stresses. We think that in the era of the $21^{\text {st }}$ century where molecular tools are being incorporated at every step in all the field of studies, which genes are expressed under drought stresses in various plant species and which genes are playing their active part in plant growth improvement while Si usage and uptake by plant should be focused. This can take us to modify genetically economically significant crops to generate the drought stress tolerant cultivar which can be very beneficial in the future. Moreover, in all the studies, Si supplementation was in the form of potassium/calcium/sodium silicate. The need is to separate the Si from other anions and it can be applied at indigenous levels so that we may better understand the particular role of Si during plant development. 
Funding. This research was funded by the Modern Agricultural Industry Technology System of China via grant number CARS-170208.

Acknowledgements. We acknowledge the Modern Agricultural Industry Technology System of China for funding (CARS-170208). We want to praise the donor agencies of China for supporting this project.

\section{REFERENCES}

[1] Abdalla, M. M. (2011): Beneficial effects of diatomite on growth, the biochemical contents and polymorphic DNA in Lupinus albus plants grown under water stress. Agriculture and Biology Journal of North America 2: 207-220.

[2] Abid, M., Hakeem, A., Shao, Y., Liu, Y., Zahoor, R., Fan, Y. et al. (2018): Seed osmopriming invokes stress memory against post-germinative drought stress in wheat (Triticum aestivum L.). - Environmental and Experimental Botany 145: 12-20.

[3] Ahmad, F., Aziz, T., Maqsood, M. A., Tahir, M. A., Kanwal, S. (2007): Effect of silicon application on wheat (Triticum aestivum L.) growth under water deficiency stress. - Emirates Journal of Food and Agriculture 19(2): 1-7.

[4] Ahmed, M., Qadeer, U., Aslam, M. A. (2011): Silicon application and drought tolerance mechanism of sorghum. - African Journal of Agricultural Research 6: 594607.

[5] Ahmed, M., Qadeer, U., Ahmed, Z. I., Hassan, F. (2016): Improvement of wheat (Triticum aestivum) drought tolerance by seed priming with silicon. - Archives of Agronomy and Soil Science 62: 299-315.

[6] Ali, Q., Haider, M. Z., Iftikhar, W., Jamil, S., Javed, M. T., Noman, A. et al. (2016): Drought tolerance potential of Vigna mungo L. lines as deciphered by modulated growth, antioxidant defense, and nutrient acquisition patterns. - Brazilian Journal of Botany 39: 801-812.

[7] Amin, M., Ahmad, R., Basra, S., Murtaza, G. (2014): Silicon induced improvement in morpho-physiological traits of maize (Zea mays L.) under water deficit. - Pakistan Journal of Agricultural Sciences 51(7): 187-196.

[8] Amin, M., Ahmad, R., Ali, A., Hussain, I., Mahmood, R., Aslam, M. et al. (2016): Influence of silicon fertilization on maize performance under limited water supply. Silicon 10(2): 1-7.

[9] Arshad, M., Ali, S., Noman, A., Ali, Q., Rizwan, M., Farid, M. et al. (2016): Phosphorus amendment decreased cadmium $(\mathrm{Cd})$ uptake and ameliorates chlorophyll contents, gas exchange attributes, antioxidants, and mineral nutrients in wheat (Triticum aestivum L.) under Cd stress. - Archives of Agronomy and Soil Science 62: 533-546.

[10] Asgharipour, M. R., Mosapour, H. (2016): A foliar application silicon enhances drought tolerance in fennel. - JAPS, Journal of Animal and Plant Sciences 26: 10561062.

[11] Bae, E.-J., Hong, A., Choi, S.-M., Lee, K.-S., Park, Y.-B. (2017): Silicon pretreatment alleviates drought stress and increases antioxidative activity in Kentucky bluegrass. - International Turfgrass Society Research Journal 13: 591-600.

[12] Biju, S., Fuentes, S., Gupta, D. (2017): Silicon improves seed germination and alleviates drought stress in lentil crops by regulating osmolytes, hydrolytic enzymes and antioxidant defense system. - Plant Physiology and Biochemistry 119: 250-264.

[13] Blum, A. (2017): Osmotic adjustment is a prime drought stress adaptive engine in support of plant production. - Plant, Cell \& Environment 40: 4-10.

[14] Calvo-Polanco, M., Sánchez-Romera, B., Aroca, R., Asins, M. J., Declerck, S., Dodd, I. C. et al. (2016): Exploring the use of recombinant inbred lines in combination with 
beneficial microbial inoculants (AM fungus and PGPR) to improve drought stress tolerance in tomato. - Environmental and Experimental Botany 131: 47-57.

[15] Cao, B., Ma, Q., Zhao, Q., Wang, L., Xu, K. (2015): Effects of silicon on absorbed light allocation, antioxidant enzymes and ultrastructure of chloroplasts in tomato leaves under simulated drought stress. - Scientia Horticulturae 194: 53-62.

[16] Cao, B., Wang, L., Gao, S., Xia, J., Xu, K. (2017): Silicon-mediated changes in radial hydraulic conductivity and cell wall stability are involved in silicon-induced drought resistance in tomato. - Protoplasma 254: 2295-2304.

[17] Chen, W., Yao, X., Cai, K., Chen, J. (2011): Silicon alleviates drought stress of rice plants by improving plant water status, photosynthesis and mineral nutrient absorption. - Biological trace element research 142: 67-76.

[18] Crusciol, C. A. C., Pulz, A. L., Lemos, L. B., Soratto, R. P., Lima, G. P. P. (2009): Effects of silicon and drought stress on tuber yield and leaf biochemical characteristics in potato. - Crop Science 49: 949-954.

[19] Dann, E. K., Le, D. P. (2017): Effects of silicon amendment on soilborne and fruit diseases of avocado. - Plants 6: 51.

[20] de Camargo, M. S., Bezerra, B. K. L., Vitti, A. C., Silva, M. A., Oliveira, A. L. (2017): Silicon fertilization reduces the deleterious effects of water deficit in sugarcane. - Journal of Soil Science and Plant Nutrition. http://dx.doi.org/10.4067/S0718-95162017005000008.

[21] Debona, D., Rodrigues, F. A., Datnoff, L. E. (2017): Silicon's role in abiotic and biotic plant stresses. - Annual Review of Phytopathology. DOI: 10.1146/annurevphyto-080516-035312.

[22] Demattê, J. L. I., Paggiaro, C. M., Beltrame, J. A., Ribeiro, S. S. (2011): Uso de silicatos em cana-de-açúcar. - Informações Agronômicas 133: 7-12.

[23] Emam, M. M., Khattab, H. E., Helal, N. M., Deraz, A. E. (2014): Effect of selenium and silicon on yield quality of rice plant grown under drought stress. - Australian Journal of Crop Science 8: 596.

[24] Eneji, A. E., Inanaga, S., Muranaka, S., Li, J., Hattori, T., An, P. et al. (2008): Growth and nutrient use in four grasses under drought stress as mediated by silicon fertilizers. - Journal of Plant Nutrition 31: 355-365.

[25] Epstein, E. (1994): The anomaly of silicon in plant biology. - Proceedings of the National Academy of Sciences 91: 11-17.

[26] Epstein, E. (1999): Silicon. - Annual Review of Plant Biology 50: 641-664.

[27] Epstein, E. (2009): Silicon: its manifold roles in plants. - Annals of Applied Biology 155: $155-160$.

[28] Epstein, E., Bloom, A. J. (2005): Mineral Nutrition of Plants: Principles and Perspectives. 2nd Ed. - Sinauer Assoc. Inc., Sunderland, UK.

[29] Fawaz, K., Mohammad, A.-C. (2013): Growth and nitrogen fixation in silicon and/or potassium fed chickpeas grown under drought and well watered conditions. - Journal of Stress Physiology \& Biochemistry 9(1): 14-27.

[30] Fukao, T., Yeung, E., Bailey-Serres, J. (2011): The submergence tolerance regulator SUB1A mediates crosstalk between submergence and drought tolerance in rice. - The Plant Cell 23: 412-427.

[31] Gao, X., Zou, C., Wang, L., Zhang, F. (2005): Silicon improves water use efficiency in maize plants. - Journal of plant nutrition 27: 1457-1470.

[32] Gao, X., Zou, C., Wang, L., Zhang, F. (2006): Silicon decreases transpiration rate and conductance from stomata of maize plants. - Journal of Plant Nutrition 29: 16371647.

[33] George, S., Manoharan, D., Li, J., Britton, M., Parida, A. (2018): Drought and salt stress in Macrotyloma uniflorum leads to common and specific transcriptomic responses and reveals importance of raffinose family oligosaccharides in stress tolerance. - Gene Reports 10: 7-16. 
[34] Gharineh, M. H., Karmollachaab, A. (2013): Effect of silicon on physiological characteristics wheat growth under Water-Deficit Stress Induced by PEG. International Journal of Agronomy and Plant Production 4: 1543-1548.

[35] Gong, H., Chen, K. (2012): The regulatory role of silicon on water relations, photosynthetic gas exchange, and carboxylation activities of wheat leaves in field drought conditions. - Acta Physiologiae Plantarum 34: 1589-1594.

[36] Gong, H., Chen, K., Chen, G., Wang, S., Zhang, C. (2003): Effects of silicon on growth of wheat under drought. - Journal of Plant Nutrition 26: 1055-1063.

[37] Gong, H., Zhu, X., Chen, K., Wang, S., Zhang, C. (2005): Silicon alleviates oxidative damage of wheat plants in pots under drought. - Plant Science 169: 313-321.

[38] Gong, H. J., Chen, K. M., Zhao, Z. G., Chen, G. C., Zhou, W. J. (2008): Effects of silicon on defense of wheat against oxidative stress under drought at different developmental stages. - Biologia Plantarum 52: 592-596.

[39] Gunes, A., Pilbeam, D. J., Inal, A., Bagci, E. G., Coban, S. (2007): Influence of silicon on antioxidant mechanisms and lipid peroxidation in chickpea (Cicer arietinum L.) cultivars under drought stress. - Journal of Plant Interactions 2: 105113.

[40] Gunes, A., Kadioglu, Y. K., Pilbeam, D. J., Inal, A., Coban, S., Aksu, A. (2008a). Influence of silicon on sunflower cultivars under drought stress, II: essential and nonessential element uptake determined by polarized energy dispersive X-ray fluorescence. - Communications in Soil Science and Plant Analysis 39: 1904-1927.

[41] Gunes, A., Pilbeam, D. J., Inal, A., Coban, S. (2008b). Influence of silicon on sunflower cultivars under drought stress, I: growth, antioxidant mechanisms, and lipid peroxidation. - Communications in Soil Science and Plant Analysis 39: 1885-1903.

[42] Guntzer, F., Keller, C., Meunier, J.-D. (2012): Benefits of plant silicon for crops: a review. - Agronomy for Sustainable Development 32: 201-213.

[43] Guo, Q., Wang, Y., Zhang, H., Qu, G., Wang, T., Sun, Q. et al. (2017): Alleviation of adverse effects of drought stress on wheat seed germination using atmospheric dielectric barrier discharge plasma treatment. - Scientific Reports 7: 16680.

[44] Habibi, G. (2014): Silicon supplementation improves drought tolerance in canola plants. - Russian Journal of Plant Physiology 61: 784-791.

[45] Hajiboland, R., Cheraghvareh, L., Poschenrieder, C. (2017): Improvement of drought tolerance in tobacco (Nicotiana rustica L.) plants by silicon. - Journal of Plant Nutrition 40: 1661-1676.

[46] Hamayun, M., Sohn, E.-Y., Khan, S. A., Shinwari, Z. K., Khan, A. L., Lee, I.-J. (2010): Silicon alleviates the adverse effects of salinity and drought stress on growth and endogenous plant growth hormones of soybean (Glycine max L.). - Pak. J. Bot. 42: $1713-1722$.

[47] Hameed, A., Sheikh, M. A., Jamil, A., Basra, S. M. A. (2013): Seed priming with sodium silicate enhances seed germination and seedling growth in wheat (Triticum aestivum L.) under water deficit stress induced by polyethylene glycol. - Pak. J. Life Soc. Sci. 11: 19-24.

[48] Hasanuzzaman, M., Nahar, K., Anee, T. I., Khan, M. I. R., Fujita, M. (2018): Siliconmediated regulation of antioxidant defense and glyoxalase systems confers drought stress tolerance in Brassica napus L. - South African Journal of Botany 115: 50-57.

[49] Hattori, T., Inanaga, S., Araki, H., An, P., Morita, S., Luxová, M. et al. (2005): Application of silicon enhanced drought tolerance in Sorghum bicolor. - Physiologia Plantarum 123: 459-466.

[50] Helaly, M. N., El-Hoseiny, H., El-Sheery, N. I., Rastogi, A., Kalaji, H. M. (2017): Regulation and physiological role of silicon in alleviating drought stress of mango. Plant Physiology and Biochemistry 118: 31-44.

[51] Hodson, M. J., White, P. J., Mead, A., Broadley, M. R. (2005): Phylogenetic variation in the silicon composition of plants. - Annals of Botany 96: 1027-1046. 
[52] Kaushal, M., Wani, S. P. (2016): Rhizobacterial-plant interactions: strategies ensuring plant growth promotion under drought and salinity stress. - Agriculture, Ecosystems \& Environment 231: 68-78.

[53] Kaya, C., Tuna, L., Higgs, D. (2006): Effect of silicon on plant growth and mineral nutrition of maize grown under water-stress conditions. - Journal of Plant Nutrition 29: $1469-1480$.

[54] Keller, C., Rizwan, M., Davidian, J.-C., Pokrovsky, O. S., Bovet, N., Chaurand, P. et al. (2015): Effect of silicon on wheat seedlings (Triticum turgidum L.) grown in hydroponics and exposed to 0 to $30 \mu \mathrm{M} \mathrm{Cu}$. - Planta 241: 847-860.

[55] Khalil, F., Rauf, S., Monneveux, P., Anwar, S., Iqbal, Z. (2016): Genetic analysis of proline concentration under osmotic stress in sunflower (Helianthus annuus L.). Breeding Science 66: 463-470. DOI: 10.1270/jsbbs.15068.

[56] Khalil, F., Naiyan, X., Tayyab, M., Pinghua, C. (2018): Screening of EMS-induced drought-tolerant sugarcane mutants employing physiological, molecular and enzymatic approaches. - Agronomy 8: 1-13. DOI: 10.3390/agronomy8100226.

[57] Khan, A., Anwar, Y., Hasan, M. M., Iqbal, A., Ali, M., Alharby, H. F. et al. (2017): Attenuation of drought stress in brassica seedlings with exogenous application of $\mathrm{Ca} 2+$ and $\mathrm{H} 2 \mathrm{O} 2$. - Plants 6: 20.

[58] Khattab, H. I., Emam, M. A., Emam, M. M., Helal, N. M., Mohamed, M. R. (2014): Effect of selenium and silicon on transcription factors NAC5 and DREB2A involved in drought-responsive gene expression in rice. - Biologia Plantarum 58: 265-273.

[59] Kim, Y.-H., Khan, A. L., Waqas, M., Lee, I.-J. (2017): Silicon regulates antioxidant activities of crop plants under abiotic-induced oxidative stress: a review. - Frontiers in Plant Science 8: 510.

[60] Kurepin, L. V, Ivanov, A. G., Zaman, M., Pharis, R. P., Hurry, V., Hüner, N. P. A. (2017): Interaction of Glycine Betaine and Plant Hormones: Protection of the Photosynthetic Apparatus during Abiotic Stress. - In: Hou, H. J. M. et al. (eds.) Photosynthesis: Structures, Mechanisms, and Applications. Springer, Berlin, pp. 185202.

[61] Kutschera, U., Niklas, K. J. (2018): Julius Sachs (1868): The father of plant physiology. - American Journal of Botany 105: 656-666.

[62] Lesk, C., Rowhani, P., Ramankutty, N. (2016): Influence of extreme weather disasters on global crop production. - Nature 529: 84-87.

[63] Lewin, J., Reimann, B. E. F. (1969): Silicon and plant growth. - Annual Review of Plant Physiology 20: 289-304.

[64] Liu, C., Yu, R., Shi, G. (2017): Effects of drought on the accumulation and redistribution of cadmium in peanuts at different developmental stages. - Archives of Agronomy and Soil Science 63: 1049-1057.

[65] Liu, P., Yin, L., Deng, X., Wang, S., Tanaka, K., Zhang, S. (2014): Aquaporinmediated increase in root hydraulic conductance is involved in silicon-induced improved root water uptake under osmotic stress in Sorghum bicolor L. - Journal of Experimental Botany 65: 4747-4756.

[66] Ma, C. C., Li, Q. F., Gao, Y. B., Xin, T. R. (2004): Effects of silicon application on drought resistance of cucumber plants. - Soil Science and Plant Nutrition 50: 623632.

[67] Ma, D., Sun, D., Wang, C., Qin, H., Ding, H., Li, Y. et al. (2016): Silicon application alleviates drought stress in wheat through transcriptional regulation of multiple antioxidant defense pathways. - Journal of Plant Growth Regulation 35: 1-10.

[68] Ma, J. F., Takahashi, E. (2002): - Soil, Fertilizer, and Plant Silicon Research in Japan. - Elsevier, Amsterdam.

[69] Ma, J. F., Yamaji, N. (2015): A cooperative system of silicon transport in plants. Trends in Plant Science 20: 435-442. DOI: 10.1016/j.tplants.2015.04.007. 
[70] Ma, J. F., Goto, S., Tamai, K., Ichii, M. (2001a). Role of root hairs and lateral roots in silicon uptake by rice. - Plant Physiology 127: 1773-1780.

[71] Ma, J. F., Miyake, Y., Takahashi, E. (2001b). Silicon as a Beneficial Element for Crop Plants. - In: Datnoff, L. E. et al. (eds.) Studies in plant Science. Elsevier, Amsterdam, pp. 17-39.

[72] Ma, J. F., Yamaji, N., Mitani, N., Tamai, K., Konishi, S., Fujiwara, T. et al. (2007): An efflux transporter of silicon in rice. - Nature 448: 209.

[73] Maghsoudi, K., Emam, Y., Pessarakli, M. (2016): Effect of silicon on photosynthetic gas exchange, photosynthetic pigments, cell membrane stability and relative water content of different wheat cultivars under drought stress conditions. - Journal of Plant Nutrition 39: 1001-1015.

[74] Marafon, A. C., Endres, L. (2013): Silicon: fertilization and nutrition in higher plants. - Embrapa Tabuleiros Costeiros-Artigo em periódico indexado (ALICE). http://www.alice.cnptia.embrapa.br/alice/handle/doc/980846.

[75] Marschner, H. (2011): Marschner's Mineral Nutrition of Higher Plants. - Academic Press, Cambridge, MA.

[76] Meena, V. D., Dotaniya, M. L., Coumar, V., Rajendiran, S., Kundu, S., Rao, A. S. (2014): A case for silicon fertilization to improve crop yields in tropical soils. Proceedings of the National Academy of Sciences, India Section B: Biological Sciences 84: 505-518.

[77] Merwad, A.-R. M. A., Desoky, E.-S. M., Rady, M. M. (2018): Response of water deficit-stressed Vigna unguiculata performances to silicon, proline or methionine foliar application. - Scientia Horticulturae 228: 132-144.

[78] Ming, D. F., Pei, Z. F., Naeem, M. S., Gong, H. J., Zhou, W. J. (2012): Silicon alleviates PEG-induced water-deficit stress in upland rice seedlings by enhancing osmotic adjustment. - Journal of Agronomy and Crop Science 198: 14-26.

[79] Mitani, N., Ma, J. F., Iwashita, T. (2005): Identification of the silicon form in xylem sap of rice (Oryza sativa L.). - Plant and Cell Physiology 46: 279-283.

[80] Mitani, N., Yamaji, N., Ago, Y., Iwasaki, K., Ma, J. F. (2011): Isolation and functional characterization of an influx silicon transporter in two pumpkin cultivars contrasting in silicon accumulation. - The Plant Journal 66: 231-240.

[81] Moro, A. L., Broetto, F., Moro, E. (2015): Antioxidative responses, physiological and productive of rice grown under water deficit and silicon fertilization. - Semina: Ciências Agrárias 36: 3013-3028.

[82] Nolla, A., Faria, R. J., Korndorfer, G. H., Silva, T. R. B. (2012): Effect of silicon on drought tolerance of upland rice. - Journal of Food, Agriculture \& Environment 10: 269-272.

[83] Noman, A., Aqeel, M. (2017): miRNA-based heavy metal homeostasis and plant growth. - Environmental Science and Pollution Research. DOI: 10.1007/s11356-0178593-5.

[84] Noman, A., Ali, S., Naheed, F., Ali, Q., Farid, M., Rizwan, M. et al. (2015): Foliar application of ascorbate enhances the physiological and biochemical attributes of maize (Zea mays L.) cultivars under drought stress. - Archives of Agronomy and Soil Science 61: 1659-1672.

[85] Ouzounidou, G., Giannakoula, A., Ilias, I., Zamanidis, P. (2016): Alleviation of drought and salinity stresses on growth, physiology, biochemistry and quality of two Cucumis sativus L. cultivars by Si application. - Brazilian Journal of Botany 39: 531-539.

[86] Paz-Kagan, T., Vaughn, N. R., Martin, R. E., Brodrick, P. G., Stephenson, N. L., Das, A. J. et al. (2017): Landscape-scale variation in canopy water content of giant sequoias during drought. - Forest Ecology and Management. https://doi.org/10.1016/j.foreco.2017.11.018. 
[87] Pei, Z. F., Ming, D. F., Liu, D., Wan, G. L., Geng, X. X., Gong, H. J. et al. (2010): Silicon improves the tolerance to water-deficit stress induced by polyethylene glycol in wheat (Triticum aestivum L.) seedlings. - Journal of Plant Growth Regulation 29: 106-115.

[88] Pereira, T. S., da Silva Lobato, A. K., Tan, D. K. Y., da Costa, D. V., Uchoa, E. B., do Nascimento Ferreira, R. et al. (2013): Positive interference of silicon on water relations, nitrogen metabolism, and osmotic adjustment in two pepper ("capsicum annuum') cultivars under water deficit. - Australian Journal of Crop Science 7: 1064.

[89] Pilon, C., Soratto, R. P., Broetto, F., Fernandes, A. M. (2014): Foliar or soil applications of silicon alleviate water-deficit stress of potato plants. - Agronomy Journal 106: 2325-2334.

[90] Ratnakumar, P., Deokate, P. P., Rane, J., Jain, N., Kumar, V., Berghe, D. V. et al. (2016): Effect of ortho-silicic acid exogenous application on wheat (Triticum aestivum L.) under drought. - Journal of Functional and Environmental Botany 6: 3442.

[91] Raven, J. A. (2001): Silicon Transport at the Cell and Tissue Level. - In: Datnoff, L. E. et al. (eds.) Studies in Plant Science. Elsevier, Amsterdam, pp. 41-55.

[92] Rizwan, M., Ali, S., Ibrahim, M., Farid, M., Adrees, M., Bharwana, S. A. et al. (2015): Mechanisms of silicon-mediated alleviation of drought and salt stress in plants: a review. - Environmental Science and Pollution Research 22: 15416-15431. DOI: $10.1007 / \mathrm{s} 11356-015-5305-\mathrm{x}$.

[93] Rizwan, M., Ali, S., Abbas, T., Adrees, M., Zia-ur-Rehman, M., Ibrahim, M. et al. (2018): Residual effects of biochar on growth, photosynthesis and cadmium uptake in rice (Oryza sativa L.) under Cd stress with different water conditions. - Journal of Environmental Management 206: 676-683.

[94] Sattar, A., Cheema, M. A., Abbas, T., Sher, A., Ijaz, M., Wahid, M. A. et al. (2017): Physiological response of late sown wheat to exogenous application of silicon. Cereal Research Communications 45: 202-213.

[95] Saud, S., Li, X., Chen, Y., Zhang, L., Fahad, S., Hussain, S. et al. (2014): Silicon application increases drought tolerance of Kentucky bluegrass by improving plant water relations and morphophysiological functions. - The Scientific World Journal 2014.

[96] Savant, N. K., Korndörfer, G. H., Datnoff, L. E., Snyder, G. H. (1999): Silicon nutrition and sugarcane production: a review. - Journal of Plant Nutrition 22: 18531903.

[97] Shen, X., Zhou, Y., Duan, L., Li, Z., Eneji, A. E., Li, J. (2010): Silicon effects on photosynthesis and antioxidant parameters of soybean seedlings under drought and ultraviolet-B radiation. - Journal of Plant Physiology 167: 1248-1252.

[98] Shi, Y., Zhang, Y., Yao, H., Wu, J., Sun, H., Gong, H. (2014): Silicon improves seed germination and alleviates oxidative stress of bud seedlings in tomato under water deficit stress. - Plant Physiology and Biochemistry 78: 27-36.

[99] Sommer, M., Kaczorek, D., Kuzyakov, Y., Breuer, J. (2006): Silicon pools and fluxes in soils and landscapes - a review. - Journal of Plant Nutrition and Soil Science 169: 310-329.

[100] Sonobe, K., Hattori, T., An, P., Tsuji, W., Eneji, A. E., Kobayashi, S. et al. (2010): Effect of silicon application on sorghum root responses to water stress. - Journal of Plant Nutrition 34: 71-82.

[101] Suzuki, N., Rivero, R. M., Shulaev, V., Blumwald, E., Mittler, R. (2014): Abiotic and biotic stress combinations. - New Phytologist. DOI: 10.1111/nph.12797.

[102] Takahashi, E., Ma, J. F., Miyake, Y. (1990): The possibility of silicon as an essential element for higher plants. - Comments on Agricultural and Food Chemistry 2: 99102. 
[103] Tale, A., Haddad, R. (2011): Study of silicon effects on antioxidant enzyme activities and osmotic adjustment of wheat under drought stress. - Czech Journal of Genetics and Plant Breeding 47: 17-27.

[104] Tamai, K., Ma, J. F. (2003): Characterization of silicon uptake by rice roots. - New Phytologist 158: 431-436.

[105] Tayyab, M., Caifang, Z., Islam, W., Khalil, F., Ziqin, P., Caifang, Z. et al. (2018a). Biochar: an efficient way to manage low water availability in plants. - Applied Ecology and Environmental Research 16: 2565-2583.

[106] Tayyab, M., Islam, W., Zhang, H. (2018b). Communications in Soil Science and Plant Analysis Promising role of silicon to enhance drought resistance in wheat. DOI: 10.1080/00103624.2018.1547394.

[107] Ullah, H., Luc, P. D., Gautam, A., Datta, A. (2017): Growth, yield and silicon uptake of rice (Oryza sativa) as influenced by dose and timing of silicon application under water-deficit stress. - Archives of Agronomy and Soil Science, 1-13.

[108] Van Bockhaven, J., De Vleesschauwer, D., Höfte, M. (2012): Towards establishing broad-spectrum disease resistance in plants: silicon leads the way. - Journal of Experimental Botany 64: 1281-1293.

[109] Wang, H.-S., Yu, C., Fan, P.-P., Bao, B.-F., Li, T., Zhu, Z.-J. (2015): Identification of two cucumber putative silicon transporter genes in Cucumis sativus. - Journal of Plant Growth Regulation 34: 332-338.

[110] Warner, K. J., Jones, G. A. (2017): A population-induced renewable energy timeline in nine world regions. - Energy Policy 101: 65-76. DOI: 10.1016/j.enpol.2016.11.031.

[111] Xu, L., Islam, F., Ali, B., Pei, Z., Li, J., Ghani, M. A. et al. (2017): Silicon and waterdeficit stress differentially modulate physiology and ultrastructure in wheat (Triticum aestivum L.). 3 - Biotech 7: 273.

[112] Yang, L., Han, Y., Li, P., Li, F., Ali, S., Hou, M. (2017): Silicon amendment is involved in the induction of plant defense responses to a phloem feeder. - Scientific Reports 7: 4232.

[113] Yin, L., Wang, S., Liu, P., Wang, W., Cao, D., Deng, X. et al. (2014): Siliconmediated changes in polyamine and 1-aminocyclopropane-1-carboxylic acid are involved in silicon-induced drought resistance in Sorghum bicolor L. - Plant Physiology and Biochemistry 80: 268-277.

[114] Zandalinas, S. I., Mittler, R., Balfagón, D., Arbona, V., Gómez-Cadenas, A. (2018): Plant adaptations to the combination of drought and high temperatures. - Physiologia Plantarum 162: 2-12.

[115] Zanetti, L. V., Milanez, C. R. D., Gama, V. N., Aguilar, M. A. G., Souza, C. A. S., Campostrini, E. et al. (2016): Leaf application of silicon in young cacao plants subjected to water deficit. - Pesquisa Agropecuária Brasileira 51: 215-223.

[116] Zang, U., Goisser, M., Häberle, K., Matyssek, R., Matzner, E., Borken, W. (2014): Effects of drought stress on photosynthesis, rhizosphere respiration, and fine-root characteristics of beech saplings: a rhizotron field study. - Journal of Plant Nutrition and Soil Science 177: 168-177.

[117] Zargar, S. M., Agnihotri, A. (2013): Impact of silicon on various agro-morphological and physiological parameters in maize and revealing its role in enhancing water stress tolerance. - Emirates Journal of Food and Agriculture 25(2): 138-141. DOI: 10.9755/ejfa.v25i2.10581.

[118] Zhang, C., Moutinho-Pereira, J. M., Correia, C., Coutinho, J., Gonçalves, A., Guedes, A. et al. (2013): Foliar application of Sili-K® increases chestnut (Castanea spp.) growth and photosynthesis, simultaneously increasing susceptibility to water deficit. - Plant and Soil 365: 211-225. 
[119] Zhang, W., Xie, Z., Wang, L., Li, M., Lang, D., Zhang, X. (2017): Silicon alleviates salt and drought stress of Glycyrrhiza uralensis seedling by altering antioxidant metabolism and osmotic adjustment. - Journal of Plant Research 130: 611-624.

[120] Zia, Z. (2018): Crop protection silicon mitigates biotic stresses in crop plants: A review. - Crop Protection 104: 21-34. DOI: 10.1016/j.cropro.2017.10.008. 